\title{
Penerapan Skema Modulasi Stabil Pada Penyelesaian Persamaan Diferensial Bernoulli
}

\author{
Ali Yunus Rohedi* \\ Laboratorium Optoinformatika, Jurusan Fisika FMIPA \\ Institut Teknologi Sepuluh Nopember, Kampus ITS Sukolilo-Surabaya, 60111
}

\begin{abstract}
Intisari
Penyelesaian persamaan diferensial Bernoulli (PD Bernoulli) secara tradisi selalu dilakukan melalui prosedur linierisasi dengan menggunakan fungsi transformasi Bernoulli. Pada makalah ini diperkenalkan teknik baru penyelesaian PD Bernoulli tanpa melibatkan prosedur linierisasi, yang didasarkan pada penerapan skema modulasi stabil. Penerapan metode yang dinamakan SMT (Stable Modulation Technique) atau teknik modulasi stabil tersebut dimulai dengan memecah PD Bernoulli atas bagian linier dan taklinier, kemudian menuliskan solusi bagian takliniernya dalam bentuk fungsi termodulasi yang nilai awalnya disamping diperankan sebagai suku amplitudo (A) juga dimodulasikan di dalam fungsi fasa F(A). Solusi eksak PD Bernoulli diberikan dalam formula $\mathrm{AF}(\mathrm{A})$, yang diperoleh setelah menggantikan solusi bagian linier ke dalam nilai awal fungsi termodulasi solusi bagian takliniernya. Pada paper ini dicontohkan penggunaan SMT pada penyelesaian PD Bernoulli untuk model penyimpanan energi magnet di dalam induktor.
\end{abstract}

KATA KUNCI: teknik modulasi stabil, fungsi termodulasi, formula AF(A)

\section{PENDAHULUAN}

Persamaan diferensial taklinier homogen Bernoulli atau yang lazim dikenal dengan sebutan PD Bernoulli menjadi model utama dalam berbagai cabang bidang aplikasi. PD Bernoulli tersebut dibedakan atas derajat ketaklinierannya (n). Sebagai contoh, PD orde dua Bernoulli $(n=2)$ lazim digunakan untuk memodelkan proses pertumbuhan logistic dalam bidang ilmu hayati [1] dan perilaku chaos [2]. Untuk orde taklinier ketiga $(\mathrm{n}=3)$ PD Bernoulli membentuk persamaan Gizbun-Landau atau persamaan quartic yang lazim digunakan dalam menelaah proses terjadinya korosi [3]. PD Bernoulli juga merupakan bagian taklinier PD parsial Klein Gordon yang dikenal sangat luas pemakaiannya, diantaranya untuk mempelajari dinamika partikel-partikel elementer dan Stokastik resonan [4], penelaahan transportasi fluxon [5], pembangkitan laser squeezed [6].

Sebagaimana lazim dijelaskan pada pustaka matematika [7, 8], penyelesaian PD Bernoulli selalu dilakukan melalui proses linierisasi sesuai dengan yang dirokemendasikan oleh Jacob Bernoulli. Transformasi dari PD takliner ke dalam PD linier dilakukan dengan menggunakan "fungsi transformasi Bernoulli", yang selanjutnya diselesaikan dengan metode penyelesaian PD linier. Baru-baru ini Rohedi [9] telah melaporkan pembuktian definisi fungsi transformasi Bernoulli tersebut, serta menjustifikasi solusi umum PD Bernoulli yang tertera dalam berbagai pustaka matematika. Pada makalah tersebut diperkenalkan Teknik Modulasi Stabil (selanjutnya disingkat SMT) yang difokuskan untuk menyelesaikan PD Bernoulli berkoefisien konstan (koefisien linier dan koefisien

*E-MAIL: rohediephysics.its.ac.id takliniernya bernilai konstan), khususnya penyelesaian yang dimulai dari titik ordiner (ordinary-point $=$ perubah bebas bernilai nol). Rohedi [10] juga melaporkan pengembangan penerapan SMT untuk penyelesaian PD Ricatti berkoefisien konstan dengan suku takhomogen perubah bebasnya berupa fungsi sinusoidal, juga dimulai dari titik ordiner. Pada makalah ini, penerapan SMT dikembangkan untuk penyelesaian PD Bernoulli berkoefisien linier dan taklinier sembarang, baik yang bernilai konstan maupun yang bervariasi sebagai fungsi dari perubah bebasnya. Dalam matematika, persamaan diferensial ini dikenal sebagai The general homogeneous Bernoulli differential equation.

\section{TEKNIK MODULASI STABIL (SMT)}

Pengembangan Teknik Modulasi Stabil (SMT) sebagai teknik baru penyelesaian PD Bernoulli dengan tanpa melibatkan prosedur linierisasi tersebut merupakan salah satu justifikasi terhadap solusi persamaan diferensial taklinier terintegralkan (An integrable nonlinear differential equations) yang penulis "aksiomakan" dalam bentuk fungsi termodulasi. Sebagaimana akan ditunjukkan, dengan menggunakan "fungsi transformasi rohedi", PD Bernoulli tersebut menjadi terintegralkan.

Ide pengembangan SMT diinspirasi oleh keberhasilan $\mathrm{Wu}$ dkk. [11] dalam membangkitkan pulsa soliton orde dasar, dengan cara mengerahkan laser ke dalam bahan magnet tertentu melalui mekanime modulasi takstabil (modulation instability). Secara matematis, bentuk pulsa soliton orde dasar tersebut merupakan fungsi penyelesaian PD parsial taklinier SchrÖdinger (NLS equation) dengan nilai awal berupa fungsi secant hyperbolic yang dikenal sebagai "pulsa masukan" soliton. Secara fisis pulsa soliton orde dasar yang tidak berubah bentuk di sepanjang jarak perambatannya di dalam medium 
fiber optik yang tidak memiliki rugi-rugi (lossless) daya tersebut, terlaksana "berkat" kemampuannya dalam memodulasi fasa secara mandiri (self-phase modulation) [12].

Beberapa tahun terakhir ini, skema modulasi takstabil diminati banyak peneliti untuk menyelesaikan persamaan NLS bahkan untuk pulsa masukan bukan soliton (non soliton pulse), yaitu dengan mengkombinasikan pemakaian $L a-$ grangian dan pendekatan variational [13]. Teknik lain yang juga lazim digunakan untuk penyelesaian persamaan NLS adalah metode Split FFT (Fast Fourier Transform), yang didasarkan pada pemecahan persamaan NLS atas bagian PD linier dan bagian PD taklinier (selanjutnya disebut bagian linier dan taklinier) kemudian menyelesaikan keduanya secara silih berganti dengan menerapkan skema transformasi Fourier cepat $[14,15]$. Penerapan skema modulasi yang mendasari pengembangan SMT dalam menyelesaikan PD Bernoulli ini didasarkan pada keterintegralan PD Bernoulli sebagaimana persamaan NLS untuk orde dasar. Namun, karena sifat kehomogenan PD Bernoulli, maka tidak diperlukan lagi penerapan skema Split FFT dan pendekatan variational, berikut uji kestabilannya. Sebagaimana akan dipaparkan dalam perumusan berikut, SMT dapat memberikan solusi eksak PD Bernoulli setelah solusi bagian takliniernya dituliskan dalam bentuk fungsi termodulasi, kemudian menggantikan solusi bagian liniernya ke dalam nilai awal solusi bagian taklinier yang disamping berperan sebagai amplitudo juga termodulasi (terlibat) dalam fungsi fasanya.

\section{A. Penurunan Formulasi Teknik Modulasi Stabil berbasiskan PD Bernoulli}

Persamaan diferensial taklinier homogen Bernoulli yang dalam makalah ini disebut PD Bernoulli adalah dalam bentuk: $[7,8]$

$$
\frac{d y}{d x}+p(x) y=Q(x) y^{n}, \quad \mathrm{n} \neq 1
$$

dengan $\mathrm{x}$ dan $\mathrm{y}(\mathrm{x})$ masing-masing adalah perubah bebas dan takbebas, sedangkan $\mathrm{p}(\mathrm{x})$ dan $\mathrm{Q}(\mathrm{x})$ berturut-turut adalah koefisien-koefisien linier dan taklinier. Adapun $\mathrm{n}$ adalah derajad ketaklinieran sehingga harus bilangan riil dan tidak bernilai satu [16], karena untuk $\mathrm{n}=0$ Pers.(1) membentuk PD linier yang terintegralkan.

Prosedur linierisasi PD Bernoulli ke dalam PD linier dilakukan dengan menggunakan fungsi transformasi Bernoulli $z=y^{1-n}$, PD hasil transformasi tersebut berbentuk:

$$
\frac{d z}{d x}+(1-n) p(x) z=(1-n) Q(x)
$$

Pers.(2) merupakan PD linier yang takterintegralkan. Karena itu agar menjadi terintegralkan guna mendapatkan solusi $y=z^{\frac{1}{1-n}}$, maka penyelesaian Pers.(2) harus melibatkan pemakaian faktor integral, sebagaimana yang lazim dilakukan pada penyelesaian PD linier [7, 8, 16].

Pada makalah ini diperkenalkan fungsi transformasi rohedi: $u=y e^{\int p(x) d x}$ yang menjadikan PD Bernoulli dapat diselesaikan tanpa melibatkan prosedur linierisasi. Dengan fungsi transformasi "baru" tersebut maka PD Bernoulli tereduksi ke dalam bentuk:

$$
\frac{d u}{d x}=Q(x) e^{(1-n) \int p(x) d x} u^{n}
$$

Pers.(3) menunjukkan bahwa PD Bernoulli terkelompok atas PD taklinier biasa yang terintegralkan (An integrable nonlinear ordinary differetial equation). Dan setelah memisahkan kedua perubah $\mathrm{x}$ dan $\mathrm{u}$, kemudian mengintegralkanya maka dari Pers.(3) diperoleh :

$$
u^{1-n}=(1-n) \int Q(x) e^{(1-n) \int p(x)} d x+C
$$

dengan $\mathrm{C}$ adalah tetapan integral. Dengan mensubstitusikan kembali $u=y e^{\int p(x) d x}$ ke dalam Pers.(4), maka solusi eksak PD Bernoulli didapatkan dalam bentuk Pers.(5). Pers.(5) tepat sama dengan yang diperoleh dengan prosedur linierisasi [8, 17].

$$
\begin{aligned}
& y(x)=\left[(1-n) e^{-(1-n) \int p(x) d x} \int Q(x) e^{(1-n) \int p(x) d x} d x+C e^{-(1-n) \int p(x) d x}\right]^{\frac{1}{1-n}} \\
& y(x)=\left(C^{\frac{1}{1-n}} e^{-\int p(x) d x}\right)\left[1+(1-n) \int Q(x)\left(C^{\frac{1}{1-n}} e^{-\int p(x) d x}\right)^{-(1-n)} d x\right]^{\frac{1}{1-n}}
\end{aligned}
$$

Prinsip dasar pemecahan PD Bernoulli atas bagian linier dan taklinier yang mendasari penerapan skema modulasi stabil pada pengembangan SMT adalah diperoleh dari Pers.(5), yaitu setelah persamaan tersebut dituliskan dalam bentuk Pers.(6).
Pers.(6) bersesuaian dengan bentuk fungsi termodulasi, yaitu mengandung suku amplitudo dan fungsi fasa. Berbeda dengan fungsi gelombang yang amplitudonya selalu konstan, amplitudo fungsi termodulasi solusi PD Bernoulli tersebut se- 
lalu bervariasi terhadap perubah bebasnya, dalam hal ini

$$
A(x)=C^{\frac{1}{1-n}} e^{-\int p(x) d x}
$$

sedangkan fungsi fasanya berbentuk:

$$
F(A)=\left[1+(1-n) \int Q(x)[A(x)]^{-(1-n)} d x\right]^{\frac{1}{1-n}}
$$

Dengan demikian solusi eksak PD Bernoulli dapat pula dituliskan dalam formula AF(A). Fitur yang menarik dari fungsi termodulasi solusi eksak PD Bernoulli tersebut adalah keterlibatan suku amplitudo di dalam fungsi fasa. Dalam kontek modulasi infromasi, skema modulasi dengan suku amplitudo termodulasi di dalam fungsi fasa tidak dikenal. Karena itu pada penyelesaian PD Bernoulli ini diperkenalkan ansih istilah "Modulasi Stabil" atas ketermodulasian amplitudo (A) di dalam fungsi fasa (phase-function) $\mathrm{F}(\mathrm{A})$. Alasan inilah yang menjadikan teknik ini dinamakan Stable Modulation Technique (SMT) atau Teknik Modulasi Stabil. Selanjutnya fungsi termodulasi Pers.(6) dituliskan dalam bentuk :

$$
y(x)=y_{L}\left[1+(1-n) \int Q(x) y_{L}^{-(1-n)} d x\right]^{\frac{1}{1-n}}
$$

Tampak bahwa $y_{L}(x)=C_{L} e^{-\int p(x) d x}$ yang merupakan solusi bagian linier PD Bernoulli tersebut berperan sebagai suku amplitudo (dengan $C_{L}=C^{\left(\frac{1}{1-n}\right)}$ ), dan bila $y_{L}(x)$ digantikan dengan $y_{0 N}$, maka Pers.(9) tereduksi ke dalam bentuk :

$$
y_{N}(x)=y_{o N}\left[1+(1-n) \int Q(x) y_{o N}^{-(1-n)} d x\right]^{\frac{1}{1-n}}
$$

yang tak lain merupakan solusi bagian taklinier PD Bernoulli yang tertuliskan dalam bentuk fungsi termodulasi. Ini berarti solusi eksak PD Bernoulli dapat diperoleh dengan SMT setelah menggantikan solusi bagian linier ke dalam nilai awal solusi bagian takliniernya, yang terlebih dahulu telah dituliskan dalam bentuk fungsi termodulasi $[9,10]$.

\section{B. Prosedur Penyelesaian SMT untuk PD Bernoulli berkoefisien konstan}

Pada sub bab ini akan diberikan petunjuk pemakaian SMT pada penyelesaian PD Bernoulli untuk koefisien linier ( $p$ ) dan koefisien taklinier (Q) yang konstan, dengan nilai awal perubah bebasnya yang diperumum $\left(x_{\circ} \neq 0\right)$.

Bagian linier dari PD Bernoulli tersebut adalah dalam bentuk :

$$
\frac{d y_{L}}{d x}+p y_{L}=0
$$

dengan solusi :

$$
y_{L}(x)=C_{L} e^{-p x}
$$

dalam hal ini $C_{L}$ adalah tetapan integral bagian linier. Adapun bagian taklinier PD Bernoulli tersebut adalah :

$$
\frac{d y_{N}}{d x}=Q y_{N}^{n}
$$

dengan solusi :

$$
y_{N}^{1-n}=y_{o N}^{1-n}+\int(1-n) Q d x
$$

yang selanjutnya dituliskan dalam bentuk fungsi termodulasi

$$
y_{N}=y_{o N}\left[1+(1-n) \int y_{o N}^{-(1-n)} Q d x\right]^{\frac{1}{1-n}}
$$

(tetapan integral bagian taklinier diberikan sebagai $y_{o N}^{1-n}$ untuk memastikan fungsi termodulasi tersebut beramplitudo $\left.y_{o N}\right)$. Setelah mensubstitusikan $y_{L}(x)$ pada Pers.(12) ke dalam $y_{o N}$ pada Pers.(15) maka diperoleh solusi umum :

$y(x)=C_{L} e^{-p x}\left[1+(1-n) \int Q C_{L}^{-(1-n)} e^{(1-n) p x} d x\right]^{\frac{1}{1-n}}$

Solusi umum pada Pers.(16) ini dapat langsung diperoleh dari fomula $\mathrm{AF}(\mathrm{A})$ pada Pers.(7) dan Pers.(8) di atas. Setelah menyelesaikan integral di dalam fungsi fasanya, selanjutnya Pers.(16) tereduksi ke dalam bentuk :

$$
y(x)=\left[C_{L}^{1-n} e^{-(1-n) p x}+\frac{Q}{p}\right]^{\frac{1}{1-n}}
$$

Nilai $C_{L}$ diperoleh dari penerapan nilai awal, yakni pada $\mathrm{x}=$ $\mathrm{x}_{\circ}, \mathrm{y}=\mathrm{y}_{\circ}$ ke dalam Pers.(17), yaitu :

$$
C_{L}^{1-n}=\left(y_{\circ}^{1-n}-\frac{Q}{p}\right) e^{(1-n) p x 。}
$$

Dari hasil substitusi $C_{L}$ dalam Pers.(18) ke dalam Pers.(17), maka solusi eksak PD Bernoulli berkoefisien konstan didapatkan dalam bentuk :

$$
y(x)=\left[\left(y_{\circ}^{1-n}-\frac{Q}{p}\right) e^{-(1-n) p(x-x \circ)}+\frac{Q}{p}\right]^{\frac{1}{1-n}}
$$

Hingga saat ini formula eksak dalam Pers.(19) tidak dijumpai dalam berbagai pustaka matematika, bahkan dalam solusi perangkat lunak simbolik sekalipun. Walaupun solusi umum PD Bernoulli telah diberikan dalam Pers.(5), namun nilai tetapan integral $\mathrm{C}$ dalam formula tersebut masih belum terdefinisi. Karena itu sebagaimana pada dua makalah sebelumnya [9, 10], Pers.(19) diperkenalkan sebagai RohediSmart Formula untuk PD Bernoulli berkoefisien konstan.

\section{APLIKASI TEKNIK MODULASI STABIL PADA PEMECAHAN MODEL PENYIMPANAN ENERGI MAGNET KE DALAM INDUKTOR}

Banyak problem fisika yang termodelkan dalam persamaan diferensial taklinier biasa orde satu. Salah satu gejala fisika termodelkan atas PD Bernoulli yang tanpa disadari telah "sangat akrab" dengan fisikawan adalah gejala transien pada proses penyimpanan energi magnet ke dalam induktor, sebagaimana terepresentasi dalam rangkaian listrik R-L berikut : 


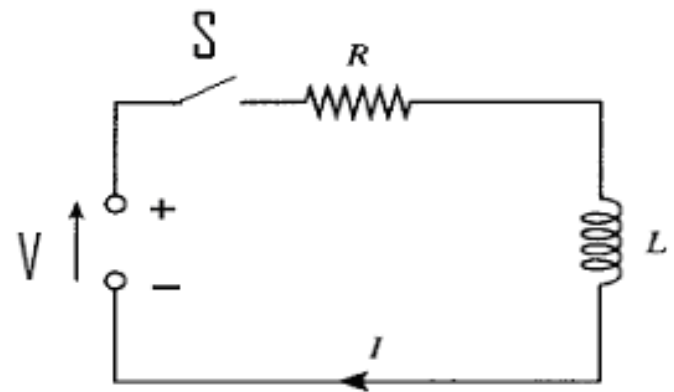

Gambar 1: Rangkaian listrik R-L untuk penyimpanan energi magnet dalam induktor

Model matematis yang mereprentasikan gejala transien tersebut terbangun dari Hukum Kirchoff [18], yang memfatwakan bahwa jumlahan beda potensial antar ujung-ujung semua elemen listrik di dalam simpal tertutup (loop) adalah $\sum \Delta V=0$, yaitu :

$$
V-i R-L \frac{d i}{d t}=0
$$

dengan $\mathrm{V}$ adalah beda potensial sumber, $\mathrm{R}$ adalah tahanan listrik, $\mathrm{L}$ adalah induktansi diri induktor, i adalah arus listrik yang mengalir dalam rangkaian, sedangkan $\frac{d i}{d t}$ adalah laju perubahan arus listrik sesaat setelah saklar (S) ditutup. Pers.(20) lazim dituliskan dalam bentuk PD linier :

$$
\frac{d i}{d t}=\frac{V}{L}-\frac{R}{L} i
$$

Cara yang lazim digunakan untuk mendapatkan nilai arus listrik setiap saat $i(t)$ adalah dengan pemisahan perubah $t$ dan i, yaitu :

$$
\frac{d i}{\frac{V}{L}-\frac{R}{L} i}=d t
$$

kemudian dilanjutkan dengan pengintegralan kedua ruas :

$$
-\frac{L}{R} \ln \left(\frac{V}{L}-\frac{R}{L} i\right)=t+C
$$

Penerapan nilai awal $\mathrm{t}=0, \mathrm{i}_{\circ}=0$ (tepat saat saklar ditutup) memberikan nilai tetapan integral $C=-\frac{L}{R} \ln \left(\frac{V}{L}\right)$. Setelah memasukkan nilai $\mathrm{C}$ ke dalam Pers.(23), maka solusi eksak Pers.(21) untuk aliran arus listrik selama pengisian energi magnet didapatkan dalam bentuk :

$$
i(t)=\frac{V}{R}\left(1-e^{-\frac{R}{L} t}\right)
$$

Untuk menyelesaikan Pers.(21) dengan SMT, maka persamaan diferensial linier tersebut harus dipandang sebagai persamaan diferensial taklinier. Pers.(21) pada dasarnya merupakan bentuk PD Bernoulli dengan derajad ketaklinieran nol $(\mathrm{n}=0)$, yaitu :

$$
\frac{d i}{d t}+p i=Q i^{0}
$$

dengan $p=\frac{R}{L}$ dan $Q=\frac{V}{L}$. Karena itu prosedur penyelesaian Pers.(25) dengan SMT dapat dilakukan mengikuti langkah dari Pers.(11) hingga Pers.(19). Oleh karena koefisien linier dan taklinier PD Bernoulli dalam Pers.(25) keduanya konstan, maka solusi SMT yang diperoleh dapat dikomparasikan langsung dengan solusi RohediSmart Formula dalam Pers.(19). Dalam hal ini perubah tak bebas y bersesuaian dengan i, sedangkan perubah bebas $\mathrm{x}$ bersesuaian dengan $\mathrm{t}$, yaitu :

$$
i(t)=\left[\left(i_{\circ}-\frac{V / L}{R / L}\right) e^{\frac{R}{L}(1-0)(0-t)}+\frac{V / L}{R / L}\right]^{\frac{1}{1-0}}
$$

Dengan demikian arus yang mengalir dalam rangkaian R-L menurut solusi SMT adalah :

$$
i(t)=-\frac{V}{R} e^{-\frac{R}{L} t}+\frac{V}{R}
$$

Cara lain untuk menjustifikasi bahwa pengisian energi magnet dalam Pers.(21) tersebut benar-benar dapat dimodelkan dengan PD Bernoulli, maka haruslah dituliskan dalam derajad ketaklinieran selain $\mathrm{n}=0$. Bentuk PD Bernoulli tersebut adalah :

$$
\frac{d\left(i^{2}\right)}{d t}+2 \frac{R}{L}\left(i^{2}\right)=2 \frac{V}{L}\left(i^{2}\right)^{1 / 2}
$$

yang diperoleh setelah mengalikan kedua ruas Pers.(21) dengan i dan memindahkan suku liniernya ke ruas kiri. Sekarang perubah takbebas PD Bernoulli tersebut berganti menjadi $i^{2}$, dengan koefisien linier $p=2 \frac{R}{L}$ dan koefisien taklinier $Q=2 \frac{V}{L}$, sedangkan derajad ketaklinierannya adalah $n=1 / 2$. Dari substitusi $\mathrm{p}, \mathrm{Q}$, dan $n$ ke dalam Pers.(19) yang dalam hal ini $y \rightarrow i^{2}$ dan $x \rightarrow t$ didapatkan :

$$
i^{2}(t)=\left[\left(\left(i_{\circ}^{2}\right)^{1 / 2}-\frac{2 V / L}{2 R / L}\right) e^{-\frac{1}{2} 2 \frac{V}{L}(t-0)}+\frac{2 V / L}{2 R / L}\right]^{2}
$$

yang bersesuaian dengan bentuk solusi :

$$
i(t)=-\frac{V}{R} e^{-\frac{R}{L} t}+\frac{V}{R}
$$

Tampak bahwa solusi Pers.(30) dan Pers.(27) tepat sama dengan solusi eksak dalam Pers.(24). Model PD Bernoulli tidak dapat digunakan untuk pelucutan energi magnet dalam induktor, karena sesaat setelah V dilepas maka Pers.(21) dan Pers.(28) keduanya tereduksi ke dalam PD linier terintegralkan. Dengan demikian Rohedismart formula dalam Pers.(26) dan Pers.(29) tidak lagi dapat digunakan.

Keeksakan solusi SMT untuk PD linier model pengisian energi magnet dalam Pers.(21) dapat dijadikan dasar penerapan SMT langsung pada PD linier hasil transforsmasi Bernoulli dalam Pers.(2). Bagian linier PD tersebut adalah

$$
\frac{d z_{L}}{d x}+(1-n) p(x) z_{L}=0
$$

dengan solusi :

$$
z_{L}=C_{L} e^{-\int(1-n) p(x) d x}
$$


dengan $C_{L}$ integral solusi bagian linier, sedangkan bagian takliniernya adalah :

$$
\frac{d z_{N}}{d x}=(1-n) Q(x)
$$

yang solusi fungsi termodulasinya adalah dalam bentuk :

$$
z_{N}=z_{\circ N}\left[1+(1-n) \int Q(x) z_{\circ N}^{-1} d x\right]
$$

dengan $z_{\circ N}$ adalah tetapan integral yang bersesuaian dengan nilai awal solusi bagian taklinier. Solusi PD Pers.(2) tersebut didapatkan setelah menggantikan $z_{L}$ ke $z_{\circ N}$, yaitu :

$$
\begin{aligned}
& \qquad \begin{aligned}
z & =z_{L}\left[1+(1-n) \int Q(x) z_{L}^{-1} d x\right] \\
\text { atau } & \\
\qquad(x) & =C_{L} e^{-(1-n) \int p(x) d x}\left[1+(1-n) \int Q(x)\left(C_{L}\right)^{-1} e^{\int(1-n) p(x) d x} d x\right]
\end{aligned}
\end{aligned}
$$

dan

$$
y(x)=\left[C_{L} e^{-(1-n) \int p(x) d x}+(1-n) e^{-(1-n) \int p(x) d x} \int Q(x) e^{\int(1-n) p(x) d x} d x\right]^{\frac{1}{1-n}}
$$

Pers.(36) merupakan solusi PD transformasi Bernoulli pada Pers.(2) dalam formula AF(A). Solusi eksak PD Bernoulli dalam Pers.(1) diperoleh setelah mensubstitusikan fungsi transformasi Bernoulli $\mathrm{z}=\mathrm{y}^{1-n}$ ke Pers.(36), dan didapatkan Pers.(37). Pers.(37) tepat sama dengan solusi eksak yang diperoleh dengan teknik konvensional yang tertera pada Pers.(5) manakala tetapan $C_{L}=C^{\frac{1}{1-n}}$.

\section{DISKUSI}

Sebagaimana telah dijabarkan, penyelesaian PD Bernoulli dengan Teknik Modulasi Stabil (SMT) yang didasarkan pada penerapan skema modulasi stabil memberikan solusi eksak yang tepat sama dengan yang diperoleh melalui prosedur linierisasi. Justifikasi kesamaan bentuk solusi eksak tersebut ditunjukkan melalui kesamaan solusi RohediSmart Formula (salah satu produk SMT) dengan yang diperoleh melalui metode integral pada penyelesaian PD Bernoulli berkoefisien konstan untuk model pengisian energi magnet ke dalam induktor.

Fitur utama yang diperoleh dari penerapan skema modulasi stabil pada penyelesaian PD Bernoulli adalah didapatkannya salusi PD taklinear biasa dalam fungsi termodulasi AF(A), yaitu suatu fungsi penyelesaian yang mirip dengan fungsi gelombang tetapi suku amplitudonya (A) juga termodulasi ke dalam fungsi fasa $\mathrm{F}(\mathrm{A})$. Penerapan skema modulasi stabil pada penyelesaian PD Bernoulli ini dapat dijadikan dasar bagi pengembangan SMT dalam menyelesaikan PD taklinier orde satu atau yang lebih tinggi, baik yang terkelompok atas PD biasa maupun PD parsial.

\section{SIMPULAN}

Dari penjabaran dan pembahasan yang telah dilakukan dapat disimpulkan beberapa hal

1. PD Bernoulli $\frac{d y}{d t}+\mathrm{p}(\mathrm{x}) \mathrm{y}=\mathrm{Q}(\mathrm{x}) \mathrm{y}^{n}$ terintegralkan secara langsung dengan menggunakan fungsi tranformasi rohedi $\mathbf{u}=\mathrm{y} \mathrm{e}^{\int p(x) d x}$.

2. Penerapan skema modulasi stabil dengan "ansih" solusi dalam bentuk fungsi termodulasi $\mathrm{AF}(\mathrm{A})$ memberikan solusi eksak PD Bernoulli yang tepat sama dengan yang diperoleh menggunakan teknik penyelesaian konvensional. Dalam hal ini suku amplitudo berupa solusi bagian linier :

$$
A(x)=C_{L} e^{-\int p(x) d x}
$$

sedangkan fungsi fasanya adalah :

$F(A)=\left[1+(1-n) \int Q(x)[A(x)]^{-(1-n)} d x\right]^{\frac{1}{1-n}}$

dengan $C_{L}$ adalah tetapan integral yang ditentukan melalui penerapan nilai awal.

3. Penyelesaian PD Bernoulli memberikan fitur skema modulasi "baru" yaitu skema modulasi stabil, dengan amplitudo yang termodulasi ke dalam fungsi fasa, sebagaimana terepresentasi pada formula $\mathrm{AF}(\mathrm{A})$. 
[1] Welner, U., Models in Biology, on the Basic Application of Mathematics and Statistics in Biological Sciences, page 66.UMK Torun (2004).

[2] Barger,V., Olson,M., Classical Mechanics A Modern Prespective, Second Edition, Chapter 11, page 391, McGrawHill,INC(1995).

[3] Hongbo, D., Zhongxiao, P., and Seeber, ICSE, I (1999).

[4] Morales,L.,Mollina, arXiv:Cond-mat/0510704v2 , 30 Nov, 2005.

[5] Gonzile, J.A., Marcano,A., Mello, B.A., Trujiloo,L., arXiv:Cond-mat/0510187v1, 7 oct (2005).

[6] Friberg, S.R, Machida, S, Werner M.J, Levanon, A, and Mukai,T., Physical Review Letters, vol 77, (18), pages : 37753778, 28 october (1996).

[7] Boas,M.L.,Mathematical Methods In The Physical Sciences, Second Edition, Chapter 8, page : 350, John Wiley \& Sons, Inc (1983).

[8] Harper,C.,Introduction to Mathematical Physics, Chapter 5 page: 157 Prentice-Hall of India (1978).

[9] Rohedi,A.Y., Solving of the homogeneus nonlinear differential equation by using Stable Modulation Technique, Conducted on the Symposium Mathematical Analysis and its Applications, Department of Mathematics, Natural Sciences, ITS, Surabaya, 1011 August (2006).

[10] Rohedi,A.Y, Analytical Solution Of The Ricatti Differential
Equation For High Frequency Derived By Using The Stable Modulation Technique, Supported on Internartional Conference of Mathematics and Natural Sciences, Poster Edition, Faculty of Natural Sciences, ITB, Bandung, 29-30 Nopember (2006).

[11] Wu,M, Carl E, Patton, and Kalinikos, B,A., International Conference on Non Linear Waves, Integrable System, and Application, Univercity of Colorado, at Boulder June 4-8 (2005).

[12] Agrawal,G.P., Application of Nonlinear Fiber Optics, Academic Press, San Diego (2001).

[13] Rapti, Z, Kevredikis, P.G, Smersi, A, and Bishop, A.R, arXiv:Cond-mat/0404601(2004).

[14] Kaczmark,T, and Kaczmark, Scientific- Proceedings of RGA Technical University., Series Computer Sicence (2001).

[15] Hall,B., Aspect of Wave and Interaction In Nonlinear Media, Thesis For The Degree of Doctor of Phylosophy, Chalmers, Gteborg, Sweden (2005).

[16] Bronshon, Differential Equations R, Schaum's easy outline, Page:14,.McGawHill Company (2003).

[17] Spiegel,M.R.,Mathematical Handbook of Formulas and Tables, Schaum's Outline Series, McGRAW-Hill Book Company, page 104 (1968).

[18] Tipler,P.A, FISIKA untuk sains dan Teknik, Jilid 2, Edisi ketiga, hal : 301-308, Penerbit Airlangga (2001). 